\title{
Arzneimittel
}

\section{Kostendämpfung durch stringente Vertragspolitik}

- Krankenkassen und Arzneimittelhersteller sollen für innovative Arzneimittel grundsätzlich innerhalb eines Jahres Verträge über Preise schließen. Nutzen- und Kosten-Nutzen-Bewertungen sollen beschleunigt werden. Kurzfristig können Preismoratorien und erhöhte gesetzliche Rabatte festgesetzt werden. Diese Instrumente werden gegenwärtig vom Bundesministerium für Gesundheit (BMG) zur Ausgabenbegrenzung in der Arzneimittelversorgung erwogen, wie aus einem Arbeitspapier hervorgeht, das der „Ärzte Zeitung“ vorliegt.

Darin werden die Vorschläge der Pharma-Verbände - Verhandlungslösungen, Preiskorridore, Abschaffung der Rabattverträge für Generika - ebenso verworfen wie die Forderung des GKV-Spitzenverbandes nach Einführung einer Vierten Hürde, bei der die Erstattung einer Arzneimittel-Innovation nur nach einer Nutzenbewertung möglich sein soll. Nach dem Vorschlag aus dem BMG soll es beim freien Marktzugang bleiben. Die Unternehmen sollen den Preis eines neuen Arzneimittels autonom festsetzen können.

Zeitnah soll allerdings eine Nutzenbewertung stattfinden. Dazu soll das Unternehmen möglichst zur Markteinführung ein Dossier einreichen, auf dessen Basis in kurzer Frist eine Nutzenbewertung erarbeitet wird. Damit soll festgestellt werden, für welche Patienten und bei welchen Krankheiten ein Zusatznutzen besteht, ob es Vergleichspräparate gibt oder ob es sich um einen Solisten (ohne Therapiealternative) handelt. Für letztere soll jede Krankenkasse mit dem Hersteller eine Erstattungsvereinbarung in freien Verhandlungen treffen. Dabei kann die Ablösung der Kosten-Nutzen-Bewertung und der Richtgrößenprüfung vereinbart werden.

Das Festbetragssystem soll erhalten bleiben. Abgelehnt wird die Abschaffung der Rabattverträge, wie Pro Generika das fordert. Allerdings sollen flankierende Regelungen zur Sicherung des Wettbewerbs getroffen werden. Das Ziel ist, dass genügend Anbieter im Markt verbleiben und dass keine Oligopolisierung des Marktes entsteht.

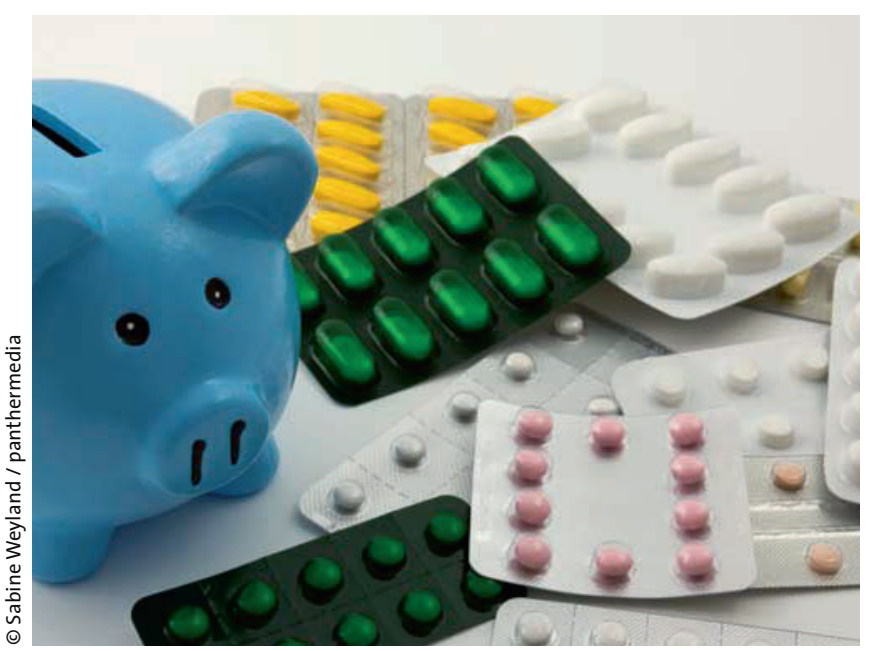

